SISTEMA
ELETRÔNICO
DE REVISTAS
SER I UfPR

\title{
Desigualdades nos padrões de acesso à água e limites da cidadania hídrica em comunidades rurais do semiárido
}

\section{Inequalities in water access patterns and limits of water citizenship in rural communities in the semi-arid region}

\author{
Luis Henrique CUNHA ${ }^{1 *}$ \\ 1 Universidade Federal de Campina Grande, Campina Grande, PB, Brasil. \\ *E-mail para contato: luishcunha@uol.com.br
}

Artigo recebido em 30 de abril de 2020, versão final aceita em 06 de outubro de 2020, publicado em 18 de dezembro de 2020

RESUMO: Este artigo aborda três dimensões da problemática do acesso à água em comunidades rurais do semiárido brasileiro: a teórica, a pública e a distributiva. Argumenta-se que as principais perspectivas utilizadas para enquadrar o problema da água na região - seja a da crise hídrica global, da construção social do desastre da seca ou da convivência com o semiárido - representam diferentes versões de um "paradigma da oferta", em que a insuficiência de água dá significado às situações sociais a serem enfrentadas. Analisa-se, então, os padrões de acesso à água potável para abastecimento humano que resultaram das ações executadas no âmbito de dois programas públicos destinados a aumentar a oferta de água nestas comunidades rurais por meio da construção de cisternas para aproveitamento de água de chuva e da implementação de sistemas de dessalinização de águas subterrâneas salinas ou salobras: o Programa de Formação e Mobilização Social para a Convivência com o Semiárido: um Milhão de Cisternas Rurais (P1MC) e o Programa Água Doce. Finalmente, defende-se uma perspectiva que enfatize questões distributivas, destacando desigualdades de diversas ordens e permitindo uma nova territorialização do problema do acesso à água no Nordeste, rompendo a separação entre rural e urbano para significar a problemática do acesso à água enquanto desigualdade estrutural, cotidianamente vivenciada, o que permite revelar conflitos ambientais latentes, a serem superados a partir da mobilização política em torno da noção de cidadania hídrica.

Palavras-chave: conflitos ambientais distributivos; abastecimento de água; espaços rurais; cidadania hídrica. 
ABSTRACT: This article addresses three dimensions of the problem of access to water in rural communities in the Brazilian semi-arid region: theoretical, public and distributive. It is argued that the main perspectives used to frame the water problem in the region - be it the global water crisis, the social construction of the drought disaster or "living with the semi-arid region" - represent different versions of a "supply paradigm", in which insufficient water supply gives meaning to the social situations to be faced. Thus, an analysis is performed on the patterns of access to drinking water for human supply that resulted from actions carried out under two public programs aimed at increasing the supply of water in the rural communities through the construction of cisterns to collect rain water and the implementation of saline or underground water desalination systems: One million Rural Cisterns (P1MC) and the Água Doce Program. Finally, a perspective is advocated that emphasizes distributional issues, highlighting inequalities of different types and allowing a new territorialization of the problem of access to water in the Northeast, breaking the dichotomy between rural and urban to signify the problem of access to water as structural inequalities, experienced daily, which makes it possible to reveal latent environmental conflicts, to be overcome from the political mobilization around the notion of water citizenship.

Keywords: distributive environmental conflicts; water supply; rural spaces; water citizenship.

\section{Introdução}

Nas primeiras décadas do Século XXI, o tema do acesso à água ganhou importância geopolítica e econômica crescente, associado às preocupações sobre os efeitos dos processos de mudança climática e aos riscos de concretização de uma "crise hídrica global". No semiárido brasileiro, este período foi marcado pela adoção de políticas e programas liderados pela sociedade civil organizada e por diferentes instâncias do poder público para ampliar a oferta de água e promover a segurança hídrica nas comunidades rurais da região, marcada pela ocorrência de secas periódicas associadas a graves emergências sociais. Da escala global à escala regional, o tema da escassez se impôs: a falta de água se constituiu como o principal problema a ser enfrentado. É possível pensar o tema do acesso à água, porém, a partir de outros referenciais. Mesmo que se considere a questão da oferta de água como uma variável importante, uma alternativa aos enquadramentos dominantes da escassez é priorizar, como tema de investigação e de luta política, a visibilização da desigualdade do acesso à água e a serviços sanitários como uma das dimensões estruturantes das relações cotidianas entre diferentes grupos sociais. Assim, seria possível transitar da ideia de segurança hídrica para a noção de cidadania hídrica.

A noção de cidadania hídrica (Castro et al., 2017) está mais diretamente associada a conflitos distributivos, ou seja, aqueles relacionados a lutas pela superação de "graves desigualdades sociais em torno do acesso e da utilização dos recursos naturais" (Zhouri \& Laschefski, 2010, p. 18). Acompanha, assim, a politização do tema da água nas últimas décadas, contrapondo-se seja às vertentes tecnicistas do ambientalismo que tornam invisíveis as assimetrias de poder que caracterizam a gestão das águas, seja aos esforços de legitimação do tratamento da água como mercadoria.

No semiárido brasileiro, o tema do acesso à água para abastecimento humano em comunidades rurais muito raramente tem sido pensado nos termos da desigualdade, sendo um pouco mais comum o tema da expropriação da água em contextos específicos de modernização econômica (Rigotto et al., 2016; Ferreira et al., 2016). Na verdade, esta é uma 
tendência mais geral da literatura sobre acesso à água em comunidades rurais no Brasil (Neves \& Mendonça, 2020), que dificulta considerar a precariedade estrutural do acesso à água nestes espaços, em particular para abastecimento humano, quando comparada a padrões de acesso existentes entre setores de classes médias e altas nos espaços urbanos. Há, inclusive, a tendência a romantizar formas comunitárias de gestão das águas em comunidades rurais (Galizoni \& Ribeiro, 2011; 2013), onde a reciprocidade prevaleceria sobre assimetrias e desigualdades, e mesmo quando da eclosão de conflitos internos à comunidade, estes se explicariam por situações de escassez e divergências políticas.

Este artigo discute os limites dos esforços de democratização do acesso à água nas áreas rurais do semiárido brasileiro nas duas primeiras décadas do século XXI, tomando como objeto de análise os padrões de acesso à água potável para abastecimento humano que resultaram das ações do Programa Água Doce (PAD), criado em 2004 no âmbito do Ministério do Meio Ambiente, e do Programa de Formação e Mobilização Social para a Convivência com o Semiárido: um Milhão de Cisternas Rurais (P1MC), coordenado a partir de 2000 pela Articulação Semiárido Brasileiro(ASA) ${ }^{1}$ e apoiado posteriormente pelo governo federal, por intermédio do então Ministério do Desenvolvimento Social e Combate à Fome.

As ações do PAD e do P1MC (entre outras iniciativas voltadas a garantir o abastecimento de água em comunidades rurais do semiárido brasileiro) representaram, sem dúvida, mudanças importantes no enfrentamento do problema do acesso à água pelas populações rurais do interior do Nordeste. As mais de 600 mil cisternas implantadas pelo P1MC e os cerca de mil sistemas de dessalinização postos em operação pelo Programa Água Doce ampliaram significativamente as infraestruturas hídricas nestes espaços rurais, impactando de forma positiva a vida de milhares de famílias. Quando se considera, porém, os padrões de acesso à água que estas ações fizeram emergir - em termos de quantidade, qualidade e regularidade do abastecimento -, percebe-se que há ainda um longo caminho a ser percorrido para que se garanta de modo efetivo a democratização do acesso à água nas comunidades rurais do semiárido. Enormes desigualdades no acesso à água ainda persistem.

Ao focar as desigualdades de acesso, a noção de cidadania hídrica permite debater o "problema" da água em termos distributivos - como alternativa ao enquadramento dominante da "crise hídrica" fundada em representações da escassez - e pode contribuir para reorientar não apenas a ação pública, mas também as reivindicações dos movimentos sociais que têm pautado o tema do acesso à água no Nordeste.

O trabalho articula três dimensões interconectadas da problemática do acesso à água em comunidades rurais do semiárido: a teórica, a pública e a distributiva. Argumenta-se que as principais perspectivas utilizadas para enquadrar o problema da água na região - seja a da crise hídrica global, da construção social do desastre da seca ou da convivência com o semiárido - representam diferentes

\footnotetext{
${ }^{1}$ A formação da ASA remete à década de 1990, como forma de fortalecer a ação das organizações da sociedade civil na região semiárida. Atualmente agrega mais de três mil organizações, como sindicatos rurais, associações de agricultores e agricultoras, cooperativas, entre outras, com atuação em todos os estados do Nordeste e em Minas Gerais.
} 
versões de um "paradigma da oferta", em que a insuficiência de água dá significado às situações sociais a serem enfrentadas. Analisa-se, então, os padrões de acesso à água associados às ações do PAD e do P1MC nas comunidades rurais do semiárido, que objetivaram aumentar a oferta de água nestas comunidades rurais por meio da construção de cisternas para aproveitamento de água da chuva ou pela instalação de sistemas de dessalinização de águas subterrâneas salinas ou salobras. Finalmente, defende-se uma perspectiva que enfatize questões distributivas, destacando desigualdades de diversas ordens e permitindo uma nova territorialização do problema do acesso à água no Nordeste, rompendo a separação entre rural e urbano para ressignificar a problemática do acesso à água enquanto desigualdade estrutural, cotidianamente vivenciada, o que permite revelar conflitos socioambientais ainda pouco explorados pelos pesquisadores das ciências sociais dedicados a esta temática.

\section{Os enquadramentos da escassez: um problema teórico}

O modo pelo qual se percebe a realidade é teórico, à medida que depende de categorias e modelos de explicação e interpretação dos eventos, fatos, fenômenos ou acontecimentos que se deseja conhecer. A operacionalização de uma teoria - como forma de perceber o mundo - produz o que chamo de enquadramentos, ou seja, a seleção daqueles aspectos da realidade que serão efetivamente mobilizados para conhecer algo. Todo enquadramento implica, portanto, incluir certas características e deixar outras fora do quadro. Como sugere Tilly (2003), categorias importam e estão intrinsicamente ligadas à perpetuação, no tempo, das desigualdades.
Edwards (2013) e Hussein (2018) chamam a atenção para o fato de que as soluções para o problema do acesso à água dependem de como esta questão é construída social e discursivamente. Se a escassez é construída como um problema de oferta, esse enquadramento irá, certamente, influenciar as medidas adotadas para solucionar o problema. Mas o discurso da escassez não é neutro. Ele responde a interesses e visões de mundo que abrem possibilidades de intervenção e descartam outras maneiras de construir o problema e, também, outras soluções (Hussein, 2018).

No semiárido, a problemática do acesso à água tem sido enquadrada, historicamente, nos termos da escassez. O problema a ser enfrentado, nestes enquadramentos dominantes, é a falta ou a pequena disponibilidade de água para uso humano ou produtivo numa região marcada por baixas médias pluviométricas e estiagens recorrentes. Mais recentemente, seguindo tendência internacional, esta retórica da escassez tem adotado a terminologia da crise hídrica.

O debate em torno do acesso à água em escala global tem se constituído, principalmente, em torno da noção de uma crise hídrica global (global water crisis), que enfatiza o problema da escassez. A UN Water, instância de coordenação, no âmbito da Organização das Nações Unidas, sobre o tema da água e saneamento, define escassez tanto em termos físicos quanto de acesso, em virtude de falhas institucionais ou ausência de infraestrutura adequada para oferta regular de água à população em diferentes regiões do planeta. De acordo com a UN Water, "o uso da água tem crescido globalmente a uma taxa duas vezes maior que a do que incremento populacional no último século, e um crescente número de regiões está alcançando o limite no qual 
os serviços de água podem ser ofertados de forma sustentável, especialmente nas regiões áridas"2.

No Relatório Mundial das Nações Unidas sobre Desenvolvimento dos Recursos Hídricos publicado em 2020, com o tema água e mudança climática, há 13 menções diretas ao termo desigualdade (inequality) ao longo de 235 páginas, contra 41 menções à expressão segurança hídrica (water security), 63 ao conceito de vulnerabilidade (vulnerability) e 73 à expressão disponibilidade de água (water availability). As referências à desigualdade, porém, são majoritariamente a aspectos econômicos: pobreza e desigualdade potencializariam vulnerabilidades em contexto de mudança climática e pressionariam os sistemas de abastecimento de água. Há uma única menção à desigualdade de acesso à água e serviços sanitários (UNESCO, 2020).

Este modelo dominante de enquadramento dos desafios relativos ao acesso à água no século XXI expressa uma abordagem do problema associada a um "paradigma da oferta", em que a crise hídrica global é, fundamentalmente, provocada pela diminuição do estoque de água doce no mundo, em virtude do consumo crescente e de soluções técnicas e gerenciais ineficientes. Por outro lado, a ênfase sobre a escassez tem ocorrido de modo simultâneo aos esforços de constituição de um mercado global desregulado de água, promovendo a mercantilização da água por meio de processos de privatização de serviços de distribuição e saneamento e de mudanças nas legislações nacionais para negar o caráter de bem público e o direito social à água.

Num contexto marcado pela intensificação dos processos de comodificação da água (Castro,
2013), em que o neoliberalismo se consolida como modelo global de governança caracterizado pela concorrência como norma universal das condutas (Laval \& Dardot, 2016), não se pode compreender a ênfase na escassez descolada da razão neoliberal. Ao contrário, a neoliberalização da natureza, ainda que não tenha introduzido no debate da água este tema, depende, grandemente, da mobilização do discurso da escassez (Edwards, 2013).

Ao estudar o caso australiano, Edwards (2013) identifica três discursos dominantes mobilizados para explicar a escassez de água no país: as influências da aridez climática (discurso preponderante até o início dos anos 1980); as deficiências dos mecanismos de gestão (discurso que ganha aceitação pública na década de 1980, na esteira do debate sobre modernização ecológica) e os efeitos das mudanças climáticas (que passam a organizar os discursos sobre escassez naquele país a partir do século XXI). A mudança no modelo de explicação da escassez de água resultou em transformações nas ações públicas para enfrentar o "problema", da ênfase sobre a oferta de água para o desenvolvimento, passando por medidas que focaram o uso eficiente da água, até as mais recentes medidas de privatização da água. Em se tratando do semiárido brasileiro, as mudanças discursivas e nas políticas públicas parecem seguir também este padrão, especialmente nos discursos técnicos (Campos, 2014), bem como a ênfase recente nos mecanismos de mercado para gerir o problema da escassez.

Mahayni (2013), como outros autores associados à ecologia política e aos estudos críticos do desenvolvimento, questiona a ideia de iminência

\footnotetext{
${ }^{2}$ http://www.unwater.org/water-facts/scarcity/, acessado em abril de 2019.
} 
de uma crise hidrológica global. Segundo ele, as representações hegemônicas da escassez de água se opõem às diferentes realidades materiais em localidades particulares. A conceituação de escassez de água expressaria escolhas políticas que definem quais variáveis importam, com ênfase recente na degradação dos sistemas de água e em processos de mudança climática, explicações estas que obscurecem as dinâmicas de poder em múltiplas escalas e ignoram as complexas realidades sociais, econômicas e políticas que condicionam a distribuição, o acesso e o uso da água.

Se na corrente hegemônica do debate sobre o acesso à água o tema da escassez organiza não apenas a percepção do problema, como também as medidas a serem adotadas para resolvê-lo, as perspectivas críticas sobre a problemática do acesso à água no semiárido nordestino desenvolvidas a partir da década de 1980 não têm conseguido escapar a este enquadramento. Mesmo adotando a perspectiva de que problemas de acesso à água não são técnicos ou naturais, mas políticos e sociais (Castro, 2007), pesquisadores e ativistas associados ao pensamento crítico têm reforçado o "paradigma da oferta" em detrimento de um "paradigma distributivo" para pensar o acesso à água no semiárido.

Sob influência da teoria da construção social dos desastres, desenvolveu-se a ideia de que as recorrentes estiagens registradas na região só se convertem no desastre da seca em virtude das vulnerabilidades de suas populações, especialmente aquelas que vivem nos espaços rurais. Uma das vulnerabilidades mais destacadas foi justamente a precariedade do acesso à água em comunidades difusas do semiárido nordestino, associada a vulnerabilidades econômicas e de representação política. Esta perspectiva contribuiu significativamente para a superação da ideia da seca como um problema natural, abrindo espaço para que se pensasse o fenômeno em termos de desigualdades históricas, tanto sociais quanto econômicas. No que se refere ao tema do acesso à água, porém, não se avançou no sentido de pensar esta problemática em termos distributivos, já que esta dimensão da vulnerabilidade reforçou a ideia de escassez de água como problema a ser enfrentado (Rebouças, 1997; Campos, 1997; Melo, 1999; Finan \& Nelson, 2001; Marengo, 2008; Melo et al., 2009; Lindoso, 2013; Andrade et al., 2013).

Numa outra perspectiva, setores da sociedade civil organizada e da academia passaram a defender a noção de convivência com o semiárido, já na década de 1990, como abordagem alternativa ao que se identificou como um "paradigma de combate à seca". Opondo-se fortemente às soluções hidráulicas baseadas em grandes obras de infraestrutura, os defensores da convivência com o semiárido ${ }^{3}$ advogaram a necessidade de abordar a problemática do acesso à água no semiárido nordestino, especialmente nas áreas rurais, numa escala local de intervenção, com ações que permitissem adaptações às condições ecológicas da região. Também esta abordagem abriu a possibilidade de pensar desigualdades estruturais em termos regionais, já que as grandes obras hídricas reforçavam desigualdades entre espaços rurais e urbanos, e nos espaços rurais, entre setores associados ao agronegócio exportador

\footnotetext{
${ }^{3}$ Meneses (2020) demonstra que frações da elite pecuarista do Nordeste também investiram discursivamente, a partir da década de 1980, num paradigma de convivência com as secas, fundado em ideais de rusticidade e adaptação às condições naturais do semiárido. Esta pesquisa reforça os limites do potencial emancipatório da noção de convivência como meio de transformação social na região.
} 
e à agricultura familiar (Silva, 2003; Duque, 2008; Diniz \& Piraux, 2011). Na escala local, porém, prevaleceu a "naturalização" da escassez de água como parte do ambiente semiárido (Cruz et al., 2018), impedindo assim que o acesso à água nas comunidades rurais fosse pensado a partir de uma perspectiva distributiva (limitada, normalmente, à desigualdade de acesso à terra como problema a ser combatido), comum às vivências cotidianas de parcelas significativas de populações urbanas na região, abrindo espaço para a legitimação de um padrão de acesso à água nas áreas rurais muito aquém da realização do direito a uma cidadania hídrica plena.

Cunha \& Paulino (2014) ressaltam dois outros aspectos da abordagem da convivência com o semiárido que limitam seu potencial crítico: de um lado, suas premissas “conservantistas", resultantes da tentativa de fundar seu potencial de inovação em visões tradicionalistas; e, de outro lado, ao priorizar ações voltadas para as parcelas historicamente marginalizadas das populações rurais da região (o que chamam de "excepcionalismo dos pobres"), tem pequeno potencial para propor projetos políticos que incluam outros grupos sociais marginalizados (especialmente moradores das periferias urbanas) e suas relações com as diferentes frações da elite regional.

As premissas teóricas da crise hídrica global, da construção social do desastre da seca e da convivência com o semiárido, ao constituírem diferentes versões do tema da escassez, dificultam o enquadramento do acesso à água em termos distributivos. Em oposição aos pressupostos do "paradigma da oferta", é necessário considerar as desigualdades históricas nos padrões de acesso à água como parte das desigualdades estruturais que organizam as relações entre classes sociais nas sociedades contemporâneas e também diferenças de gênero, étnico-raciais, entre outras. Para muitas populações nas diferentes regiões do planeta, a vivência da crise hídrica, como situação rotineira de suas vidas, expressa-se pela dificuldade de garantir a democratização do acesso à água, em termos de quantidade, qualidade e regularidade do abastecimento.

Nas duas próximas seções, explora-se a crítica aos enquadramentos da escassez na construção do problema da democratização do acesso à água nas comunidades rurais do semiárido nas dimensões pública (relativa às políticas de ampliação da oferta de água para consumo humano junto às populações dos espaços rurais) e distributiva (em que se busca refletir sobre as implicações normativas de uma perspectiva teórica que substitua o discurso dominante da escassez pela superação das desigualdades relativas ao exercício do direito à água).

\section{Limites das ações para democratização do acesso à água no semiárido}

As décadas de 1990 e 2000, no semiárido brasileiro, foram marcadas por esforços de elaboração tanto de discursos renovados para fundamentar ações voltadas ao desenvolvimento regional quanto de formulação e execução de políticas públicas consideradas inovadoras. Esses discursos e essas políticas alimentaram-se fortemente das críticas produzidas às estratégias de combate à seca e às grandes políticas hídricas e projetos de modernização econômica. Num cenário marcado por grande experimentação social e pelo debate em torno da sustentabilidade e da degradação ambiental (Sabourin et al., 2003), a ideia de "convivência com o semiárido" passa a ser a referência discursiva 
dominante de um conjunto muito diversificado de atores sociais. Essa ideia vai estar associada a uma grande variedade de políticas, com destaque para iniciativas de ampliação do acesso à água entre moradores das áreas rurais do semiárido brasileiro.

Um dos pontos mais criticados nas grandes obras hídricas executadas no Nordeste ao longo do século XX residia justamente na exclusão de moradores das comunidades rurais da região do acesso à água. Os grandes açudes, adutoras e estações de tratamento atendiam principalmente populações urbanas e grandes projetos econômicos privados, com pequena repercussão entre os segmentos mais pobres da população rural. $\mathrm{O}$ foco sobre os conflitos e contradições referentes ao acesso à água, o intenso debate acerca das formas mais adequadas de gestão de recursos hídricos e a anunciada crescente escassez de água potável no mundo (Silva et al., 2006) são elementos que compõem o cenário no qual passam a ser pensadas políticas públicas "inovadoras" de ampliação do acesso à água entre "camponeses" ou "comunidades difusas" do semiárido.

Na década de 1990, duas diferentes alternativas emergem como solução hídrica para comunidades rurais no semiárido brasileiro: as cisternas de placa (que armazenam água de chuva) e os sistemas de dessalinização via osmose inversa ${ }^{4}$ (que permitem o aproveitamento de águas subterrâneas salobras e salinas). Serão a base, nos anos 2000, de dois programas mantidos no âmbito do governo federal, em articulação com a sociedade civil, governos estaduais e municipais, para atender os objetivos da ampliação da oferta de água para as populações rurais.
Em 2000, a Articulação do Semiárido (ASA), com base em experiências de algumas das entidades que lhe dão sustentação, lançou o Programa de Formação e Mobilização Social para a Convivência com o Semiárido: um Milhão de Cisternas Rurais (conhecido pela sigla P1MC), com apoio do governo federal, por intermédio do Ministério do Desenvolvimento Social e Combate à Fome (MDS) (Assis, 2012). Em 2004, a então Secretaria de Recursos Hídricos (depois Secretaria de Recursos Hídricos e Ambiente Urbano) do Ministério do Meio Ambiente, em parceria com a Embrapa e a Universidade Federal de Campina Grande e com a participação das secretarias de recursos hídricos estaduais, lançou o Programa Água Doce (PAD), voltado para oferta de água via sistemas de dessalinização, com financiamentos da Petrobras, Fundação Banco do Brasil (FBB), BNDES, entre outros. Os dois programas foram incluídos no Plano Brasil sem Miséria, instituído pelo governo federal em junho de 2011. Estes dois programas, em que pese as diferenças de concepção e modelos de implementação, compartilham muitas características comuns.

O P1MC e o PAD buscaram enfrentar o problema da oferta de água potável em comunidades rurais do semiárido brasileiro com estratégias "fora do mercado", apostando na cooperação e na autogestão ou cogestão. $\mathrm{O}$ acesso à água potável ou “de qualidade" é formulado, assim, como um direito, historicamente negado a milhares de famílias residentes em comunidades rurais do semiárido brasileiro. O P1MC e o PAD podem ser interpretados como parte de um esforço mais geral de "democratização do acesso à água" no Brasil.

\footnotetext{
${ }^{4}$ Processo de separação de substâncias através de uma membrana que retém os sais e outros materiais, deixando passar a água.
} 
Estes esforços, porém, não estão isentos de conflitos e contradições. E as respostas que oferecem para as comunidades rurais do semiárido colocam em relevo os desafios da governança democrática de políticas públicas, como desdobramento da crítica que foi feita à ação estatal - tanto à direita quanto à esquerda do espectro político - nos anos 1970 e 1980 (Hager, 2012). Se a crítica ao estado abre espaço para maior protagonismo da sociedade civil na formulação e na implementação de políticas públicas, também favorece processos de desresponsabilização das instâncias estatais na oferta de serviços públicos, sendo o estado substituído pelo mercado ou pela sociedade civil. E, como demonstra Martins (2015), a ação de modelos participativos ou mais democráticos de gestão dos recursos hídricos no Brasil não impediu que se desenvolvessem e se reproduzissem desigualdades e diferenças hierárquicas nas arenas de governança das águas.

Os formuladores do P1MC e do PAD precisaram lidar com o tema da governança das águas e da gestão cotidiana da água potável nas comunidades atendidas pelos programas. As ações que promoveram ao longo de mais de uma década vinculam os temas da inovação, governança e democracia de modo empírico e experiencial, de cuja análise pode-se compreender melhor os desafios da oferta de água em comunidades rurais do interior do Nordeste.

Ainda que voltado à oferta, às populações rurais, de água potável para beber e cozinhar por meio do recurso à acumulação de água de chuva em cisternas de placas, o P1MC deveria também, no âmbito de um "movimento de articulação e de convivência sustentável com o ecossistema do se- miárido", promover o "fortalecimento da sociedade civil" e a "mobilização, envolvimento e capacitação das famílias, com uma proposta de educação processual". De acordo com a ASA,

cada cisterna tem capacidade de armazenar 16 mil litros de água. Essa água é captada das chuvas, através de calhas instaladas nos telhados. Com a cisterna, cada família fica independente, autônoma e com a liberdade de escolher seus próprios gestores públicos, buscar e conhecer outras técnicas de convivência com o semiárido e com mais saúde e mais tempo para cuidar das crianças, dos estudos e da vida, em geral ${ }^{5}$.

As ideias de autonomia, independência e liberdade são importantes neste contexto, pois informam uma visão de mundo que pressupõe que a garantia do direito à água de qualidade pode se realizar fora da esfera de influência do Estado, percebida, no geral, como perniciosa. Constrói-se, assim, uma alternativa comunitarista ao problema do acesso à água, que é um dos objetos da crítica a ser elaborada no quadro do paradigma da "cidadania hídrica".

O Programa Água Doce está organizado em torno do uso da tecnologia de dessalinização de águas subterrâneas salobras e salinas via osmose inversa. Dois principais desafios tiveram que ser enfrentados pelo PAD: as críticas ambientais à dessalinização, em virtude do concentrado salino que é produzido no processo (que produz, em média, $50 \%$ de água doce e $50 \%$ de água ainda mais salobra ou salgada, que era normalmente depositada diretamente no ambiente) e ao fato de que a grande maioria dos sistemas instalados no semiárido brasileiro desde meados dos anos 1990 se encontrava

\footnotetext{
${ }^{5}$ Os trechos entre aspas, bem como as informações sobre o P1MC, foram retirados do site da ASA Brasil (www.asabrasil.org.br), acessado em abril de 2019 .
} 
sem funcionar, colocando assim a questão da gestão como problema crucial a ser enfrentado. Havia, segundo cálculos da coordenação do programa, cerca de dois mil sistemas de dessalinização instalados no semiárido brasileiro no início da década de 2000, a grande maioria deles sem funcionar. O PAD tem realizado esforços principalmente no sentido de recuperar alguns desses sistemas, introduzindo uma nova metodologia de gestão e o destino adequado ao concentrado salino, e na elaboração de planos estaduais que orientem as ações dos governos estaduais na temática, adotando ações regulares de monitoramento e manutenção dos sistemas implantados (MMA, 2012).

Considerando o objetivo de democratização do acesso à água nas comunidades rurais do semiárido, é fundamental considerar dois aspectos interligados: os indicadores de qualidade, quantidade e regularidade do abastecimento que caracterizam as infraestruturas hídricas implantadas pelo PAD e P1MC, e o potencial destas iniciativas na redução das desigualdades de acesso à água na região.

Para o PAD, parte-se de dados coletados pelo autor do artigo com a aplicação de 120 questionários a membros das comunidades rurais atendidas pelo programa, reunidos no VIII Encontro Nacional de Formação do Programa Água Doce, realizado no mês de dezembro de 2017, em João Pessoa (PB) ${ }^{6}$. Estes 120 questionários apresentam dados de comunidades de sete estados do Nordeste: 29 da Bahia, 23 da Paraíba, 18 do Rio Grande do Norte, 15 de Alagoas, 14 do Piauí, 12 de Sergipe e 09 do Ceará. Ainda que o Ceará, junto com a Bahia, concentre grande quantidade de sistemas de dessalinização implantados pelo $\mathrm{PAD}$, as comunidades onde estes sistemas foram implantados estavam sub-representadas no encontro de formação. Apesar disso, é possível dizer que os dados levantados a partir dos questionários dão um panorama abrangente de alguns resultados alcançados pelo programa.

Cerca de $45 \%$ dos sistemas de dessalinização implantados pelo PAD (sempre de acordo com os dados dos questionários aplicados no encontro de formação realizado em João Pessoa) estão estabelecidos em localidades que concentram até 50 famílias (53 sistemas, em 120 pesquisados). Apenas 6 sistemas (5\%) funcionam em localidades com mais de 300 famílias, normalmente sedes distritais ou municipais. Localidades com 50 a 100 famílias representam 32\% dos sistemas implantados, enquanto aquelas com 100 a 300 famílias totalizam $13 \%$ do total. Cerca de $5 \%$ dos que responderam ao questionário não sabiam informar o número de famílias de suas comunidades. Estes dados são coerentes com o objetivo do programa de instalar sistemas nas comunidades rurais difusas, normalmente excluídas de outras políticas de ampliação do acesso à água em virtude justamente do pequeno número de usuários potenciais.

Quando se questiona acerca dos usuários efetivos do programa, ou seja, aqueles entre as famílias potencialmente beneficiadas que se abastecem regularmente no chafariz que distribui a água dessalinizada, um quadro diferente emerge. Em cerca de $22 \%$ das localidades, o número de famílias que usavam a água dessalinizada era inferior a $50 \%$ do total de famílias potencialmente beneficiárias do sistema. Na maior parte dos sistemas, este índice

\footnotetext{
${ }^{6}$ Entre 2005 e 2012, atuei diretamente na coordenação do componente Mobilização Social do PAD, tendo colaborado especialmente na construção dos mecanismos de gestão compartilhada dos sistemas de dessalinização implantados ou recuperados pelo programa.
} 
girava em torno de $75 \%$ na época da pesquisa. Poucos representantes comunitários afirmaram que o sistema atendia à totalidade das famílias (menos de 5\%). Vários são os motivos para o baixo índice de adesão das famílias em algumas comunidades ao sistema de dessalinização como principal fonte de água potável: grande distância de algumas casas do chafariz onde a água é distribuída; desconfiança em relação ao processo de dessalinização; concorrência com outras fontes, como as cisternas; entre outros.

Em 32,5\% das localidades, as famílias têm direito a pegar no sistema de dessalinização menos de 100 litros de água por semana. Em cerca de 10\% das comunidades, a disponibilidade é de 40 litros por semana por família. Considerando uma família de 4 pessoas, isso significa pouco menos de 1,5 litro/ dia de água por pessoa. Mesmo considerando que a água produzida pelos sistemas de dessalinização deve ser utilizada apenas para dessedentação humana, essa quantidade é pequena.

A quantidade de água produzida pelo sistema é limitada pela vazão do poço artesiano de onde a água salina ou salobra é retirada, pela capacidade de recuperação de água doce, que depende das características físico-químicas da água do poço, e, também, pelos custos de produção, concentrados especialmente no pagamento de um operador do sistema e da conta de energia elétrica. Em 79\% das comunidades cujos dados foram levantados com a aplicação do questionário, a conta de energia elétrica é paga pelas prefeituras municipais. Mas há casos ( $15 \%$ do total) em que a própria comunidade arca com este custo. Em 68\% das localidades, os operadores dos sistemas recebem algum tipo de remuneração (seja por parte da prefeitura ou da própria comunidade), mas quase $30 \%$ dos operadores trabalhavam voluntariamente na época de aplicação dos questionários.

O pagamento da conta de energia elétrica e do operador do sistema é sempre uma fonte de ameaça ao funcionamento regular dos sistemas de dessalinização. A troca de prefeito em alguns casos levou à suspensão dos pagamentos, seja da conta de energia elétrica seja do operador. A operação de um sistema de dessalinização é relativamente simples e membros das comunidades atendidas podem ser operadores eficientes. Eles são treinados pelos técnicos do PAD, que monitoram - por meio de indicadores dos sistemas - a qualidade da operação. Há casos, porém, em que os prefeitos não querem pagar os operadores escolhidos pela comunidade e treinados pelo programa. Por outro lado, há muitos operadores voluntários que apresentam alto comprometimento com suas funções. Mas é comum também que o trabalho voluntário impacte a regularidade do funcionamento dos sistemas, especialmente no tocante aos horários para entrega de água às famílias.

Quanto à regularidade da distribuição de água, há um gargalo potencial. Em $62 \%$ dos sistemas de dessalinização (da amostra de 120 da pesquisa), a distribuição de água é feita em apenas três dias da semana. Em outros 8\%, em apenas dois dias. Em apenas 4\% dos sistemas há distribuição de água todos os dias da semana. A regularidade da distribuição não parece afetar drasticamente a quantidade de água efetivamente retirada pelas famílias, que no geral se mostraram satisfeitas com o acesso à água, até porque a decisão dos dias e horários de entrega de água é da própria comunidade e consta do acordo de gestão assinado quando o sistema entra em funcionamento. A necessidade de armazenamento, 
porém, aumenta os riscos de contaminação da água, comprometendo a qualidade.

A qualidade da água ofertada à população pelos sistemas de dessalinização é um dos grandes diferenciais do Programa Água Doce quando comparado ao P1MC. Os sistemas de dessalinização retiram não apenas o excesso de sais da água, mas também bactérias e outras impurezas. Aágua que sai do dessalinizador atende aos critérios de potabilidade do Ministério da Saúde. Nos últimos anos, introduziu-se também um sistema de cloração da água para minimizar os riscos de contaminação durante $o$ armazenamento nas casas das famílias. A qualidade da água, porém, depende do bom funcionamento do sistema. Membranas desgastadas ou filtros mal manipulados comprometem a potabilidade da água. Assim, é fundamental que ocorra o monitoramento regular do funcionamento do sistema, que atualmente é feito a partir de empresas contratadas, sob supervisão de técnicos dos estados. Em 92\% dos questionários aplicados, os representantes das comunidades atendidas pelo PAD informaram que os sistemas estão sendo regularmente monitorados, o que pode ser considerado um excelente resultado.

Há uma vasta literatura sobre os resultados alcançados pelo P1MC. A leitura destes trabalhos, mesmo que não apresentem um panorama geral dos indicadores de acesso à água gerados pela implantação de cisternas, oferece uma referência apropriada para o tipo de questionamento feito neste artigo.

Gomes \& Heller (2016), a partir de pesquisa realizada no norte de Minas Gerais, concluem que o P1MC tem sido bem-sucedido em atingir suas metas de construção das estruturas físicas, mas que ainda são grandes os desafios relativos à oferta de água, tanto em termos da quantidade quanto da qualidade.
Chamam atenção, particularmente, para o fato de que, comparando-se os indicadores de acesso à água nas cidades, as cisternas nas áreas rurais apresentam piores indicadores quantitativos e qualitativos.

Em pesquisa conduzida no interior da Paraíba, Santos et al. (2013) também registram que as águas de chuva armazenadas nas cisternas não são suficientes para suprir as necessidades das famílias, que recorrem a carros-pipa para atender as demandas por água. É justamente em virtude da mistura de água da chuva com água dos carros-pipa que Morais (2016) explica o alto índice de contaminação das cisternas em Sergipe por coliformes fecais. Silva \& Borja (2017) defendem que é necessário realizar estudos mais sistemáticos acerca do volume per capita de água oferecida pelas cisternas para as famílias a partir da captação de água de chuva. Estes trabalhos, entre outros, ajudam a problematizar o padrão de acesso à água produzido pela estratégia de captar água de chuva para abastecimento humano.

As ações realizadas, tanto pelo Programa Água Doce quanto pelo P1MC, resultaram num padrão de acesso à água para abastecimento humano nas comunidades rurais em que estes programas atuaram - considerando indicadores de qualidade, quantidade e regularidade do abastecimento - insuficientes para a conquista de uma cidadania hídrica plena pelas populações assistidas. Não se trata, porém, de problemas com a execução dos programas. Antes, é preciso identificar as causas desses resultados nas concepções que orientaram a formulação dessas iniciativas, descoladas de objetivos associados à redução das desigualdades de acesso à água na região com vistas à universalização do direito a uma cidadania hídrica plena. 


\section{Uma perspectiva distributiva}

A partir da análise crítica das experiências de promoção da ampliação do acesso à água engendradas pelo P1MC e pelo PAD, é possível elaborar uma abordagem alternativa aos enquadramentos atualmente dominantes. Esse esforço, que além de teórico-analítico é também normativo, parte da premissa de que é necessário pensar a democratização do acesso à água em termos da identificação de territórios da desigualdade, em substituição aos pressupostos implícitos do semiárido como constituído por territórios da escassez de água. A perspectiva dos territórios da desigualdade permite romper a falsa oposição entre rural e urbano, considerando, inclusive, que a tendência nas últimas décadas tem sido a concentração das populações nos pequenos e médios municípios da região. Nestes municípios, o acesso à água tem se realizado crescentemente por meio da constituição de um mercado informal, em que se naturaliza a água como mercadoria. Nas áreas consideradas urbanas, assim como nos espaços rurais, as desigualdades de acesso à água não são situações excepcionais geradas por episódios de crise hídrica, mas parte da experiência cotidiana de parcelas expressivas da população.

É preciso que se ressalte o conflito distributivo latente às desigualdades de acesso à água. E, a partir desta premissa:

a) refletir sobre a necessidade de repensar o papel do Estado na garantia de uma cidadania hídrica comum a todos os habitantes do semiárido nordestino, destacando o risco das tendências atuais de mercantilização da água como alternativa ao colapso no abastecimento público. O problema do acesso à água é predominantemente político (Agnew, 2011). Nas sociedades democráticas, questões distributivas só podem ser adequadamente enfrentadas em termos políticos, mobilizando o Estado como ator importante na produção da justiça social. Movimentos sociais e pesquisadores envolvidos no tema da democratização do acesso à água no semiárido nordestino precisam repensar as estratégias de ação para além do mercado ou do comunitarismo. O desafio de reduzir desigualdades estruturais só pode ser adequadamente realizado a partir da mobilização das instâncias públicas de coordenação e de investimento;

b) indicar a urgência de considerar alternativas que atendam às necessidades de água para populações rurais e urbanas como parte de um mesmo esforço de democratização do acesso à água. É preciso evitar a produção de um duplo padrão de cidadania hídrica, em que populações rurais sejam atendidas em suas demandas por água potável a partir de alternativas que não garantem os mesmos padrões de quantidade, qualidade e regularidade do abastecimento esperados e exigidos para as áreas urbanas. A construção de uma cidadania hídrica universalizada depende que se evite apreender espaços rurais e urbanos como territórios distintos. Do ponto de vista do acesso à água, é possível produzir novos mapas territoriais, que coloquem em destaque aqueles territórios marcados pelas grandes desigualdades distributivas;

c) dar visibilidade aos conflitos ambientais relativos à distribuição da água entre diferentes grupos sociais na região, conflitos 
estes historicamente invisibilizados. Os estudos sobre conflitos relativos ao acesso e ao uso da água no semiárido nordestino são surpreendentemente raros, dadas as disparidades distributivas. Pereira \& Cuellar (2015), ao estudar os impactos ambientais e socioeconômicos da seca entre 2012 e 2014 no Baixo Jaguaribe (CE), revelaram o recrudescimento de conflitos de água envolvendo empresas dos perímetros irrigados, agricultores familiares, o abastecimento da região metropolitana de Fortaleza e de municípios menores, movimentos sociais de luta pela terra, entre outros. A distribuição desigual da água gera conflitos em muitos outros espaços, que precisam ser mais bem compreendidos. É necessário recuperar, também, a história de conflitos silenciados no passado, inclusive nos espaços urbanos.

\section{Considerações finais}

Defendeu-se, ao longo deste artigo, que o debate histórico sobre a problemática do acesso à água no semiárido nordestino precisa ser atualizado. Um dos pontos mais destacados do Programa Água Doce e do P1MC foi o de chamar atenção para um fato fundamental: a escassez de água no semiárido não é igual para todos. Ao destacarem a situação crítica das populações residentes em comunidades rurais difusas da região e ao empreenderem ações para combater este problema, atualizaram os discursos mais críticos sobre as secas no Nordeste, que desde há muito tempo ressaltam o impacto diferencial das estiagens prolongadas sobre os mais pobres. Tanto o P1MC quanto o Programa Água Doce optaram por produzir meios alternativos de acesso à água (cisternas e sistemas de dessalinização), no lugar de priorizar a problematização de como se dá a distribuição da água acumulada nos períodos de chuva. E de, como resposta a esta problematização, efetivar ações que alterem esses padrões de acesso.

Esta opção produziu dois importantes efeitos políticos: a) tornou essas políticas praticamente inofensivas do ponto de vista das classes dominantes, até porque mesmo no auge de implementação, mobilizaram uma parcela pequena de recursos públicos; e b) impediu que se produzisse um movimento forte de luta pela democratização do acesso à água que reunisse as populações expropriadas nas áreas rurais e urbanas. É por este motivo que tanto o P1MC quanto o Programa Água Doce não escapam ao "paradigma da escassez", ou seja, a compreensão que o problema da água no Nordeste é fundamentalmente uma questão de oferta.

No quadro do paradigma da escassez incorporam, sem dúvida, elementos importantes da crítica social produzida sobre as secas na região Nordeste. Mas não se apresentam, efetivamente, pelo menos no que toca ao problema do acesso à água, como a irrupção de um novo paradigma. Não conseguiram produzir o passo necessário à superação do foco na oferta de água (no caso, da oferta de água em comunidades rurais difusas) para subordinarem o problema da oferta à questão mais geral dos padrões de distribuição da água entre os diferentes grupos sociais da região, independentemente de serem habitantes de espaços rurais ou urbanos. Politizar a água significa reabrir o debate sobre a maneira pela qual se definem padrões de acesso e mecanismos de controle do Estado e da sociedade sobre este acesso.

Os agentes, tanto da sociedade civil quanto do poder público, que estiveram envolvidos com a 
implementação do P1MC e do Programa Água Doce precisaram, desde o primeiro momento, lidar com o problema da gestão da água das cisternas e dos sistemas de dessalinização. Definir formas de acesso, maneiras de gerenciamento de recursos hídricos, responsabilidades de monitoramento e manutenção das infraestruturas hídricas eram desafios enfrentados desde o início nestes programas. Desafios que foram abordados primordialmente como questões técnico-burocráticas e muito raramente como temas propriamente políticos.

A perspectiva da ecologia política (Paulson et al., 2004), ao enfatizar os conflitos e os diferenciais de poder na conformação de padrões de acesso a recursos naturais, emerge como uma abordagem promissora para pesquisadores que desejam pensar o tema da democratização do acesso à água no semiárido em novas bases. No caso particular dos recursos hídricos, há um conjunto de trabalhos que buscam contribuir com a construção de uma ecologia política da água (Swyngedouw et al., 2002; Bakker, 2003; Budds, 2004; Castro, 2016), abordagem que precisa ainda ser desenvolvida para o semiárido brasileiro.

As respostas produzidas pelo P1MC e pelo Programa Água Doce para o problema do acesso à água nas comunidades rurais do interior do Nordeste dizem muito "sobre a condição da solidariedade social". Segundo Alexander (2014, p. 404-405), "solidariedade diz respeito ao sentido de conexão, uma questão de sentimento e significado". Ao definir como foco de ação as comunidades rurais, estes programas limitam as possibilidades de soli- dariedade que conectam populações urbanas e rurais da região, especialmente aquelas historicamente marginalizadas do acesso à água. A possibilidade de construção de um sentido de solidariedade ampliada, que Alexander chama de solidariedade civil, valoriza a criação de laços mais universais, incluindo grupos sociais aparentemente diferentes. É necessário reconectar as demandas das populações rurais num projeto civil para todos os grupos marginalizados da região.

Na problemática do acesso à água, é preciso demandar do Estado que institua um padrão homogêneo de cidadania hídrica no semiárido nordestino. Que perceba as alternativas da cisterna e dos sistemas de dessalinização como emergenciais e não como a solução dos conflitos distributivos relativos à água. Uma perspectiva mais comprometida com os instrumentos da solidariedade civil deverá reforçar conexões entre as demandas dos diversos grupos sociais marginalizados em suas lutas cotidianas por água de qualidade em quantidade socialmente aceitável, tendo como horizonte a denúncia das formas consolidadas de gestão da desigualdade do acesso à água e a construção de um padrão único de cidadania, que evite a produção de formas de acesso à água exclusivas para populações das comunidades rurais difusas do semiárido, que estão também entre as mais pobres, mas que compartilham um destino comum com parcelas importantes das populações urbanas. Ao fazer emergir territórios da desigualdade, é possível transitar de um paradigma da escassez para a politização da água em termos da justiça distributiva. 


\section{Referências}

Alexander, J. C. Lutando a respeito do modo de incorporação - Reação violenta contra o multiculturalismo na Europa. Revista Estudos Politicos, 5(2), 399-426, 2014. Disponível em: http://revistaestudospoliticos.com/wp-content/uploads/2015/04/Vol.5-N.2-p.399-426.pdf

Agnew, J. Waterpower: politics and the geography of water provision. Annals of the Association of American Geographers, 101(3), 463-476, 2011. doi: $10.1080 / 00045608.2011 .560053$

Andrade, A. J. P.; Souza, C. R.; Silva, N. M. A vulnerabilidade e a resiliência da agricultura familiar em regiões semiáridas: o caso do Seridó Potiguar. Campo-Território: Revista de Geografia Agrária, 8(15), 1-30, 2013. Disponível em: http://www.seer.ufu.br/index.php/campoterritorio/ article/view/19590

Assis, T. R. P. Sociedade civil e a construção de políticas públicas na região semiárida brasileira: o caso do programa Um Milhão de Cisternas Rurais (P1MC). Revista de Politicas Públicas, 16(1), 179-189, 2012. Disponível em: http:// www.periodicoseletronicos.ufma.br/index.php/rppublica/ article/view/1189

Bakker, K. J. A political ecology of water privatization. Studies in Political Economy, 70, 35-58, 2003. doi: 10.1080/07078552.2003.11827129

Budds, J. Power, nature and neoliberalism: the political ecology of water in Chile. Singapore Journal of Tropical Geography, 25(03), 322-342, 2004. doi: 10.1068/d9511

Campos, J. N. B. Vulnerabilidades hidrológicas do semiárido às secas. Planejamento e Políticas Públicas, 16, 261-298, 1997. Disponível em: http://www.ipea.gov.br/ppp/index. $\mathrm{php} / \mathrm{PPP} /$ article/view/120

Campos, J. N. B. Secas e políticas públicas no semiárido: ideias, pensadores e períodos. Estudos Avançados, 28(82), 65-88, 2014. doi: 10.1590/S0103-40142014000300005

Castro, J. E. The political ecology of water uncertainty and inequality: a sociological contribution. In: Dias, P. L. S.; Ribeiro, W. C.; Nunes, L. H. (Orgs.). A contribution to understanding the regional impacts of global change in
South America. São Paulo: Instituto de Estudos Avançados da USP, 2007. p. 225-245.

Castro, J. E. Water is not (yet) a commodity: commodification and rationalization revisited. Human Figurations, 2(01), 2013. Disponível em: http://hdl.handle.net/2027/ spo.11217607.0002.103

Castro, J. E. Água e democracia na América Latina. Campina Grande: EDUEPB, 2016.

Castro, J. E.; Silva, J. I. A. O.; Cunha, L. H. Os desafios da "cidadania" hídrica na América Latina: conflitos, estado e democracia.Prim@ Facie, 16(32),01-39, 2017. doi: 10.22478/ufpb.1678-2593.2017v16n32.34247

Cruz, G. C.; Ribeiro, E. M.; Galizoni, F. M. Semiárido, secas e "gerais" do norte de Minas: uma revisão da bibliografia sobre o Alto-Médio São Francisco. Campo-Território: Revista de Geografia Agrária, 13(31), 29-56, 2018. doi: 10.14393/RCT133102

Cunha, L. H.; Paulino, J. S. Convivência com o semiárido: um novo paradigma para políticas públicas no Nordeste? In: Neves, D. P.; Gomes, R. A.; Leal, P. F. (Orgs.). Quadros e programas institucionais em políticas públicas. Campina Grande: EDUEPB, 2014. p. 27-58.

Diniz, P. C. O; Piraux, M. Das intervenções de combate à seca às ações de convivência com o semiárido: trajetória de "experimentalismo institucional" no semiárido brasileiro. Cadernos de Estudos Sociais, 26(2), 227-238, 2011. Disponível em: https://periodicos.fundaj.gov.br/CAD/article/ view/1457

Duque, G. "Conviver com a seca": contribuição da Articulação do Semi-Árido/ASA para o desenvolvimento sustentável. Desenvolvimento e Meio Ambiente, 17: 133-140, 2008. doi: 10.5380/dma.v17i0.13417

Edwards, G. A. S. Shifting constructions of scarcity and the neoliberalization of australian water governance. Environment and Planning A, 45(8), 1873-1890, 2013. doi: $10.1068 / \mathrm{a} 45442$

Ferreira, M. J. M.; Viana Júnior, M. M.; Pontes, A. G. V.; Rigotto, R. M.; Gadelha, D. Gestão e uso dos recursos hí- 
dricos e a expansão do agronegócio: água para quê e para quem? Ciência \& Saúde Coletiva, 21(3), 743-752, 2016.

Finan, T. J.; Nelson, D. Making rain, making roads, making do: public and private adaptations to drought in Ceará, Northeast Brazil. Climate Research, 19(2), 97-108, 2001. Disponível em: https://www.int-res.com/articles/cr2002/19/ c019p097.pdf

Galizoni, F. M.; Ribeiro, E. M. Bem comum e normas costumeiras: a ética das águas em comunidades rurais de Minas Gerais. Ambiente \& Sociedade, 15(1), 77-94, 2011. doi: 10.1590/S1414-753X2011000100005

Galizoni, F. M.; Ribeiro, E. M. Água, terra e família: uma etnografia dos recursos hídricos nas comunidades camponesas da Mantiqueira mineira. Revista UFMG, 20(2), 68-93, 2013. Disponível em: https://www.ufmg.br/revistaufmg/ downloads/20-2/03-agua-terra-e-familia-flavia-galizoni-eduardo-ribeiro.pdf

Gomes, U. A. F.; Heller, L. Acesso à água proporcionado pelo Programa de Formação e Mobilização Social para Convivência com o Semiárido: Um Milhão de Cisternas Rurais: combate à seca ou ruptura da vulnerabilidade? Engenharia Sanitária e Ambiental, 21(3), 623-633, 2016. doi: 10.1590/ S1413-41522016128417

Hager, C. Revisiting the ungovernability debate: regional governance and sprawl in the USA and UK. International Journal of Urban and Regional Research, 36(4), 817-830, 2012. doi: 10.1111/j.1468-2427.2010.01017.x

Hussein, H. Lifting the veil: unpacking the discourse of water scarcity in Jordan. Environmental Science and Policy, 89, 385-392, 2018. doi: 10.1016/j.envsci.2018.09.007

Laval, C.; Dardot, P. A nova razão do mundo: ensaios sobre a sociedade neoliberal. São Paulo: Editora Boitempo, 2016.

Lindoso, D. P. Vulnerabilidade e adaptação da vida às secas: desafios à sustentabilidade rural familiar nos semiáridos nordestinos. Brasília, Tese (Doutorado em Desenvolvimento Sustentável) - UnB, 2013.

Mahayni, B. Producing crisis: hegemonic debates, mediations and representations of water scarcity. In: Harris, L. M.; Goldin, J. A; Sneddon, C. (Eds.). Contemporary water governance in the global South: scarcity, marketization and participation. London: Routledge, 2013. p. 35-45.

Marengo, J. A. Vunerabilidade, impactos e adaptação à mudança do clima no semiárido do Brasil. Parcerias Estratégicas, 27, 149-176, 2008. Disponível em: http://seer.cgee. org.br/index.php/parcerias_estrategicas/article/view/329

Martins, R. C. Fronteiras entre desigualdade e diferença na governança das águas. Ambiente \& Sociedade, 18(1), 221238, 2015. doi: 10.1590/1809-4422ASOC952V1812015en

Melo, J. C. O fenômeno El niño e as secas no Nordeste do Brasil. Raizes, 20, 13-21, 1999. doi: 10.37370/raizes.1999.v.162

Melo, J. A. B.; Pereira, R. A.; Dantas Neto, J. Atuação do estado brasileiro no combate à seca no Nordeste e ampliação das vulnerabilidades locais.Qu@litas, 8(2), 1-13,2009. doi: 10.18391/qualitas.v8i2.387

Meneses, V. F. “Admirável bode novo”: regionalismo e ruralismo em defesa da caprinocultura no semiárido nordestino. Estudos Sociedade e Agricultura, 28(1), 109-135, 2020. doi: 10.36920/esa-v28n1-5

MMA - Ministério do Meio Ambiente. Programa Água Doce - Documento base, 2012. Disponível em: $<$ https:// www.mma.gov.br/estruturas/212/_publicacao/212_publicacao26042011115912.pdf>. Acesso em: out. 2019.

Morais, G. F. O. Cisternas domiciliares: qualidade da água para consumo humano em comunidades rurais do semiárido sergipano. João Pessoa, Dissertação (Mestrado em Desenvolvimento e Meio Ambiente) - UFPB, 2016.

Neves, P. D. M.; Mendonça, M. R. Agrohidronegócio canavieiro: apropriação da terra e da água. Revista de Geografia, 37(1), 97-112, 2020. Disponível em: https://periodicos.ufpe. br/revistas/revistageografia/article/view/241975

Paulson, S.; Gezon, L. L.; WattS, M. Politics, ecologies, genealogies. In: Paulson, S.; Gezon, L. L. (Eds.). Political ecology across spaces, scales, and social groups. New Brunswick: Rutgers University Press, 2004. p. 17-37.

Pereira, G. R.; Cuellar, M. D. Z. Conflitos pela água em tempos de seca no Baixo Jaguaribe, Estado do Ceará. Estudos Avançados, 29(84), 115-137, 2015. doi: 10.1590/ S0103-40142015000200008 
Rebouças, A. C. Água na região Nordeste: desperdício e escassez. Estudos Avançados, 11(29), 127-154, 1997. doi: 10.1590/S0103-40141997000100007

Rigotto, R. M.; Freitas, B. M. C.; Maia, R.; Gadelha, D.; Pontes, A.; Teixeira, M.; Costa, D.; Rocha, M.; Ferreira, M.; Montezuma, T. Perímetros irrigados e direitos violados no Ceará e no Rio Grande do Norte: "por que a água chega e a gente tem que sair?" Pegada, 17(2), 122-144, 2016. doi: 10.33026/peg.v17i2.4684

Sabourin, E.; Duque, G.; Malagodi, E. Novos atores do desenvolvimento rural no semi-árido brasileiro: uma visão crítica do período 1997-2002. Raízes, 22(01), 58-72, 2003. doi: 10.37370/raizes.2003.v22.209

Santos, A. C.; Ceballos, B. S. O.; Sousa, C. M. Políticas públicas de água e participação no semiárido: limites e tensões no P1MC. Revista Eletrônica de Gestão e Tecnologias Ambientais, 1(1), 145-161, 2013. doi: 10.17565/gesta.vli1.8279

Silva, A. R.; Borja, P. C. Uso de cisternas para abastecimento humano por meio da captação de água da chuva: a experiência do Brasil nos últimos anos. Revista AIDIS de Ingeniería y Ciencias Ambientales, 10(3), 270-284, 2017. doi: 10.22201/iingen.0718378xe.2017.10.3.56746
Silva, J. B.; Ramalho, D. S.; Guerra, L. D.; Fernandes, M. Ambivalências e contradições do discurso sobre a escassez de água no Brasil e no mundo e da proposta de gestão racional de recursos hídricos. Raizes, v. 25(01/02), 26-36, 2006. doi: 10.37370/raizes.2006.v25.258

Silva, R. M. A. Entre dois paradigmas: combate à seca e convivência com o semiárido. Sociedade e Estado, 18(1-2), 361-385, 2003. doi: 10.1590/S0102-69922003000100017

Swyngedouw, E.; Kaïka, M.; Castro, J. E. Urban water: a political-ecology perspective. Built Environment, 28(02), 124-137, 2002. Disponível em: https://www.jstor.org/ stable/23288796

Tilly, C. Changing forms of inequality. Sociological Theory, 21(1), 31-36, 2003. doi: 10.1111/1467-9558.00173

UNESCO - United Nations Educational, Scientific and Cultural Organization. The United Nations World Water Development Report 2020 - Water and climate change, 2020. Disponível em: $<$ https://en.unesco.org/themes/water-security/wwap/wwdr/2020\#download $>$. Acesso em: abr. 2020.

Zhouri, A.; Laschefski, K. Desenvolvimento e conflitos ambientais: um novo campo de investigação. In: Zhouri, A.; Laschefski, K. (Orgs.). Desenvolvimento e conflitos ambientais. Belo Horizonte: Editora UFMG, 2010. p. 11-31. 